\title{
Lipoproteínas de répteis: estrutura, metabolismo e aspectos comparativos
}

\author{
Jamile da Costa Araújo ${ }^{1 *}$, Raquel Tatiane Pereira ${ }^{2}$, Maria das Dores Correia Palha $^{3} \&$ Priscila $^{4}$ \\ Vieira e Rosa ${ }^{4}$
}

${ }^{I}$ Pesquisadora da Empresa Brasileira de Pesquisa Agropecuária (EMBRAPA)

${ }^{2}$ Doutoranda do curso de Zootecnia da Universidade Federal de Lavras (UFLA)

${ }^{3}$ Professora da Universidade Federal Rural da Amazônia (UFRA)

${ }^{4}$ Professora da Universidade Federal de Lavras (UFLA)

*Autor para correspondência, E-mail: jamile.costa@embrapa.br

\begin{abstract}
RESUMO. As lipoproteínas são complexos macromoleculares esféricos de lipídeos e proteínas específicas (apoproteínas), sendo as principais: quilomicrons, lipoproteína de muito baixa densidade (VLDL), lipoproteína de baixa densidade (LDL) e lipoproteína de alta densidade (HDL). Elas diferem-se na composição lipídica e proteica, no tamanho e na densidade. A separação das mesmas pode ser efetuada por meio de ultracentrifugação, onde a densidade é usada como parâmetro de separação, ou por eletroforese em gel de agarose, usando a propriedade eletroforética como parâmetro, em: $\alpha$-lipoproteína (HDL), pré- $\beta$-lipoproteína (VLDL) e $\beta$-lipoproteína (LDL). Nesta revisão objetiva-se abordar a importância do metabolismo das lipoproteínas em répteis e como o mesmo se dá, além de particularidades nos diferentes grupos de animais que integram esta classe. As características das lipoproteínas em répteis variam, de acordo com a ordem e espécie animal, porém em todas as espécies observa-se certa similaridade com as lipoproteínas humanas, inclusive a presença de homólogos de várias apoproteínas humanas. Porém, as informações sobre esse complexo molecular ainda são escassas, quando se pensa na grande diversidade da classe Reptilia, necessitando assim de mais estudos, principalmente com os répteis submetidos à alimentação oferecida pelo homem, como os animais de finalidade produtiva e os abrigados em zoológicos. Lembrando que distúrbios no metabolismo dos lipídeos também podem ocorrer, resultando em diversas patologias, como obesidade, e consequentemente redução do desempenho produtivo e reprodutivo.
\end{abstract}

Palavras-chave: Apoproteína, distúrbio, VLDL, LDL, HDL

\section{Reptil lipropoteins: Structure, metabolism and comparative aspects}

\begin{abstract}
Lipoproteins are spherical macromolecular complexes of lipids and specific proteins (apoproteins), the main ones being: chylomicrons, very low density lipoprotein (VLDL), low density lipoprotein (LDL) and high density lipoprotein (HDL). They differ in the lipid and protein composition, size and density. The separation of the same can be done through ultracentrifugation, where the density is used as a separation parameter, or by electrophoresis on agarose gel electrophoresis using the property as a parameter, in: $\alpha$-lipoprotein (HDL), pre- $\beta$-lipoprotein (VLDL) and $\beta$-lipoprotein (LDL). In this review we aimed to address the importance of metabolism of lipoproteins in reptiles and how it occurs, and its peculiarities in different groups of animals that are part of this class. The characteristics of the lipoproteins in reptiles vary in accordance with the order and animal species, but in all species there is a similarity with human lipoproteins, including the presence of several human homologues of apoproteins. However, the information on this molecular complex is scarce, when we consider the great diversity of the class Reptilia, thus requiring further studies, especially with reptiles subjected to food offered by humans, like animals in a productive purpose and housed in zoos. Recalling that disturbances in lipid metabolism may also occur, resulting in various diseases, such as obesity, and consequently reducing the productive and reproductive performance.
\end{abstract}

Keywords: Apoprotein, disorder, VLDL, LDL, HDL 


\section{Introdução}

O Brasil tem a fauna e flora mais ricas de toda a América Central e do Sul, mas a maioria das informações sobre répteis é ainda preliminar. Atualmente existem cerca de 650 espécies de répteis no Brasil: 330 cobras, 230 lagartos, 50 anfisbenídeos, seis jacarés e 35 tartarugas (Rodrigues, 2005). E dentre esses animais podemos encontrar diversos hábitos alimentares, entre eles o herbívoro, carnívoro e onívoro.

Em geral, a carne de animais silvestres contém níveis bastante reduzidos de lipídeos totais e apresenta uma alta proporção de ácidos graxos poliinsaturados em relação a ácidos graxos saturados (Sinclair \& O'Dea, 1990). Principalmente quando em vida-livre, onde podem escolher seu próprio alimento (Crawford et al., 1981).

Fisiologicamente, sabe-se que a gordura absorvida da dieta e os lipídeos sintetizados pelo fígado e tecido adiposo devem ser transportados para os vários tecidos e órgãos, para utilização e armazenamento. Uma vez que os lipídeos são insolúveis em água, surge o problema de como transportá-los em um ambiente aquoso, o plasma sanguíneo. Isto é solucionado pela associação de lipídeos não polares (triacilgliceróis e ésteres de colesterol) com lipídeos anfipáticos (fosfolipídeos e colesterol) e proteínas, resultando em lipoproteínas miscíveis em água. Estes processos embora sejam alvo crescente de estudos na área animal, tem sido mais direcionados aos animais zootécnicos, pela necessidade de se ampliar o conhecimento básico e embasar pesquisas aplicadas à nutrição e produção animal. Em animais silvestres há ainda muito o que se conhecer sobre os aspectos morfofuncionais do processo de obtenção de energia, em especial de digestão, metabolização e armazenamento e excreção das gorduras, independente do grupo animal em questão.

Apesar de sua riqueza e diversidade quanto aos recursos faunísticos nativos, a pesquisa sobre a Classe Reptilia no Brasil é ainda mais restrita quando comparada aos mamíferos e aves. Em geral, os trabalhos disponíveis abordam aspectos zoológicos e ecológicos específicos, priorizandose condições in situ ou, quando muito, zoológicos, cujos plantéis ex situ são, em geral, quantitativamente restritos. No que tange as possibilidades para o aproveitamento sustentável da diversidade faunística brasileira, o conhecimento científico e tecnológico que pode ser gerado, especialmente a partir de criadouros ex situ legalizados, em suas diversas modalidades, é enorme, embora subaproveitado. Nesses criadouros, as lacunas de investigação científica permanecem amplas, mesmo já tendo decorrido mais de 15 anos da concessão legal à criação ex situ de algumas espécies da fauna silvestre brasileira com finalidades comerciais. Ou seja, há ainda um longo caminho científico a percorrer para que se possam validar as indicações de opções ex situ como alternativas viáveis à conservação e ao aproveitamento da diversidade faunística, em bases sustentáveis. Percebe-se, infelizmente, que temas como o metabolismo digestivo e a nutrição em répteis, são ainda pouco visados cientificamente e, mais especificamente, as lipoproteínas em répteis e seu metabolismo, são ainda mais obscuros. Desta forma, objetiva-se nesta revisão abordar a importância das lipoproteínas em répteis e como se dá o metabolismo dessas moléculas, enfatizando aspectos comparados nos diferentes grupos de animais que integram esta classe.

\section{Lipoproteínas plasmáticas}

As lipoproteínas são complexos macromoleculares esféricos de lipídeos e proteínas específicas (apolipoproteínas ou apoproteínas). As principais lipoproteínas são: quilomicrons, lipoproteína de muito baixa densidade (VLDL), lipoproteína de baixa densidade (LDL) e lipoproteína de alta densidade (HDL). Elas diferem na composição lipídica e protéica, no tamanho e na densidade (Champe et al., 2006). A separação das mesmas pode ser efetuada através de ultracentrifugação, onde a densidade é usada como parâmetro de separação, ou por eletroforese em gel de agarose, usando a propriedade eletroforética como parâmetro, em: $\alpha$-lipoproteína (HDL), pré- $\beta$-lipoproteína (VLDL) e $\beta$-lipoproteína (LDL) (Mayes, 1998).

Tais moléculas possuem um núcleo de lipídeos neutros (triacilgliceróis e ésteres de colesterol) circundado por uma camada de apoproteínas anfipáticas, fosfolipídeos e colesterol livre (não-esterificado). Esses compostos anfipáticos são orientados de forma que suas porções polares fiquem expostas na superfície da lipoproteína, tornando a partícula solúvel em meio aquoso. Os triacilgliceróis e o colesterol carregados pela lipoproteína são obtidos da dieta (fonte exógena) ou da síntese de novo (fonte endógena). Portanto, as lipoproteínas são importantes tanto para manterem solúveis 
seus componentes lipídicos, como para promoverem o eficiente mecanismo de transporte de lipídeos entre os tecidos (Champe et al., 2006).

Os quilomicrons são as lipoproteínas com menor densidade e o maior tamanho, elas contêm a maior proporção de lipídeos e a menor de proteínas, e se originam a partir da absorção intestinal de triacilgliceróis. Em ordem crescente de densidade estão as VLDLs, que se originam no fígado a fim de transportar triacigliceróis, e as LDLs, que também apresentam maiores relações de proteínas para lipídeos, e representam o estágio final de catabolismo das VLDLs. As HDLs são as lipoproteínas de maior densidade, e estão envolvidas no metabolismo das VLDL, quilomicrons e também no transporte do colesterol (Mayes, 1998; Champe et al., 2006).

As diferentes lipoproteínas trocam constantemente de lipídeos e apoproteínas umas com as outras, isso faz com que a composição de uma classe de partícula possa ser muito variável (Champe et al., 2006).

\section{Apoproteínas}

As apoproteínas associadas às lipoproteínas exercem diversas funções, como sítios de reconhecimento para receptores na superfície das células, sejam como ativadoras ou coenzimas para enzimas envolvidas no metabolismo das lipoproteínas. Algumas apoproteínas são necessárias como componentes estruturais essenciais dessas partículas e não podem ser removidas, sendo denominadas integrais, como as de tipo B, enquanto outras são livremente transferidas entre as lipoproteínas, denominadas periféricas, como as de tipo A, C e E (Champe et al., 2006; Fontes, 2009).

Em humanos, as apoproteínas podem ser classificadas pela estrutura e pela função, em cinco classes, de A a E, sendo que muitas classes apresentam subclasses. As funções, origem, peso molecular e lipoproteínas em que elas são encontradas estão expressos na Tabela 1.

Tabela 1. Apoproteínas das lipoproteínas plasmáticas humanas.

\begin{tabular}{|c|c|c|c|}
\hline Apopoproteína & Lipoproteína & $\begin{array}{c}\text { Peso } \\
\text { molecular (Da) }\end{array}$ & Comentários \\
\hline Apo A-I & HDL, quilomícrons & 28.000 & $\begin{array}{c}\text { Ativadora da LCAT. Ligante para o receptor } \\
\text { de HDL }\end{array}$ \\
\hline Apo A-II & HDL, quilomicrons & 17.000 & Possível inibidor da LCAT \\
\hline Apo A-IV & $\begin{array}{l}\text { Secretada com os quilomicrons, mas } \\
\text { transferidas para as HDLs }\end{array}$ & 46.000 & $\begin{array}{c}\text { Função desconhecida. Sintetizadas pelo } \\
\text { intestino }\end{array}$ \\
\hline Apo B-100 & LDL, VLDL, IDL & 550.000 & $\begin{array}{c}\text { Sintetizadas pelo fígado. Ligante do receptor } \\
\text { de LDL. }\end{array}$ \\
\hline Apo B-48 & $\begin{array}{l}\text { Quilomicrons e quilomicrons } \\
\text { remanescentes }\end{array}$ & 260.000 & Sintetizada no intestino. \\
\hline Apo C-I & VLDL, HDL, quilomicrons & 7.600 & Possível ativador da LCAT. \\
\hline Apo C-II & VLDL, HDL, quilomicrons & 8.916 & Ativadora da lipoproteína lipase. \\
\hline Apo C-III & VLDL, HDL, quilomicrons & 8.750 & $\begin{array}{l}\text { Várias formas polimórficas, dependendo do } \\
\text { conteúdo em ácido siálico. }\end{array}$ \\
\hline Apo D & Subfração da HDL & 19.300 & $\begin{array}{l}\text { Pode atuar como proteína de transferência de } \\
\text { lipídeos. }\end{array}$ \\
\hline Apo E & $\begin{array}{l}\text { VLDL, HDL, quilomicrons e } \\
\text { quilomicrons remanescentes }\end{array}$ & 34.000 & $\begin{array}{l}\text { Ligante do receptor dos quilomicrons } \\
\text { remanescentes no fígado e receptor da LDL. }\end{array}$ \\
\hline
\end{tabular}

Fonte: Mayes (1998)

\section{Metabolismo das lipoproteínas}

Os quilomícrons são formados nas células da mucosa intestinal e transportam triacilgliceróis, colesterol, vitaminas lipossolúveis e ésteres de colesterol da dieta para os tecidos periféricos. A partícula liberada pelas células da mucosa intestinal é denominada de quilomicron nascente, por ser funcionalmente incompleta. Ao alcançar o plasma essa partícula recebe a apo A, apo E e as apo Cs. A apo C-II ativa a lipoproteína lipase, que irá hidrolisar os triacilgliceróis carregados por essa partícula, os quais irão formar ácidos graxos livres e glicerol. Quando mais de $90 \%$ dos triacilgliceróis dos quilomicrons é degradado, as apo C e A retornam para as HDLs, sendo formado assim o quilomicron remanescente, o qual será rapidamente removido pelo fígado, cujas células possuem receptores para lipoproteínas que reconhecem a apo E. Enfim, os quilomicrons sofrem endocitose e nas células hepáticas são degradados em aminoácidos, 
colesterol livre e ácidos graxos (Champe et al., 2006).

As VLDL, produzidas no fígado, são compostas predominantemente por triacilgliceróis e sua função é carregar os lipídeos do fígado para os tecidos periféricos. São secretadas no sangue como partículas de VLDL nascentes, contendo a apo B-100, posteriormente recebem a apo E e apo C-II da HDL circulante. A apo C-II terá a mesma função que no quilomicron. Após a degradação dos triacilgliceróis a partícula fica menor e mais densa, e as apo $\mathrm{C}$ e $\mathrm{E}$ retornam às HDLs. Por fim, triacilgliceróis e ésteres de colesteróis são transferidos da VLDL para a HDL, através de mediação da proteína transferidora de ésteres de colesterol. Com tais modificações, a VLDL transforma-se em LDL, cuja principal função é prover colesterol para os tecidos periféricos, ou intermediar o retorno do mesmo ao fígado. Isto é efetuado através do reconhecimento da partícula através de receptores apo B-100/apo E (Champe et al., 2006).

A captação de LDLs também pode ser efetuada por macrófagos. A oxidação de componentes lipídicos e da apo B são modificações que fazem com o que a LDL seja reconhecida por um receptor do macrófago, receptor removedor classe A (RR-A). O acúmulo de éster colesterol nos macrófagos os transformam em "células espumosas", que participam da formação da placa aterosclerótica (Champe et al., 2006).

As HDLs são secretadas diretamente no sangue pelo fígado e pelo intestino, e desempenham diversas funções importantes como de ser reservatório de apoproteínas e de captar o colesterol não esterificado, esterificar, e fazer o transporte reverso do colesterol (Champe et al., 2006).

\section{Lipoproteínas em répteis}

As composições químicas de lipoproteínas de diferentes répteis como cobra (Liopeltis vernalis), cobra d'água de colar (Natrix natrix), varano malaio (Varanus salvator), e tartaruga grega (Testudo graeca) são comparadas entre si e com as frações correspondentes no soro humano (VLDL, d <1,006, LDL d 1,006 - 1,063, e HDL d $1,063-1,21 \mathrm{~g} / \mathrm{ml}$ ) na Tabela 2 . As frações de VLDL foram similares em seus conteúdos de lipídios neutros (triglicérides e éster colesterol) e estavam entre $60-65 \%$. A maior variação foi no teor de colesterol livre, que foi maior no VLDL da cobra d'água (13\%) e menor no homem $(6,7 \%)$. Isto foi, naturalmente, refletido nas taxas de colesterol esterificado e colesterol livre (CE/CL) que foram essencialmente as mesmas em rã-touro e homem $(1,3$ e 1,2, respectivamente), mas substancialmente inferior nas cobras (0,4) (Chapman, 1980).

Grandes variações de éster de colesterol (20,2\% na tartaruga grega) e triglicérides $(13,9 \%$ em tartaruga grega) foram observadas, embora, como em VLDL, o teor de lipídeos neutros totais tenha variado menos $(40,8 \%$ em cobra). O conjunto de proteínas e fosfolipídeos representaram uma proporção semelhante de peso total de partículas em répteis e no homem (38,3 $46,6 \%$ ), sugerindo que o pico de densidade e, portanto, distribuição de partículas totais de cada fração de LDL, apesar de isolado sobre uma densidade de largura ampla e contínua, numa mistura heterogênea de espécies moleculares, pode ser bastante semelhante (Chapman, 1980).

O teor de proteína de LDL humana foi inferior ao verificado em todas as frações dos répteis. No entanto, uma vez que a variação na distribuição de LDL está dentro do intervalo de 1,006 - 1,063 $\mathrm{g} / \mathrm{ml}$ pode facilmente explicar este achado. Estudos futuros de LDL (e VLDL) dessas (e outras) espécies devem, portanto, ser realizados em frações isoladas dentro de um estreito intervalo de densidade, por exemplo, 1,020-1,050 $\mathrm{g} / \mathrm{ml}$, ou se for inadequado, na maioria das partículas de LDL isoladas nas espécies, por exemplo, por centrifugação de gradiente de densidade (Chapman, 1980).

O HDL foi caracterizado em todas as espécies por uma alta quantidade de proteína, com exceção do varano malaio. Exclusivamente, nesta espécie, a proporção de éster de colesterol apresentou um intervalo relativamente estreito $(14,3-24,4 \%)$. A grande variação na proporção de colesterol esterificado / livre é explicada pela grande diferença, entre as espécies, nos níveis de colesterol livre do HDL. Enquanto triacilgliceróis variaram minimamente, fosfolipídios variaram amplamente, de $12,9 \%$ na tartaruga grega para $24,7 \%$ em cobra, resultando em uma grande variação no peso total de partículas polares componentes (fosfolipídeos e proteínas) de $58,7 \%$ em Natrix piscator (cobra d'água), até $76,4 \%$ em tartaruga grega. Esta descoberta pode sugerir que a natureza da maioria da HDL das espécies é um tanto variável de animal para 
animal, com sua alta ou baixa densidade sendo refletida nas proporções alteradas de tais componentes, ou, alternativamente, que o papel estrutural dessas moléculas pode não ser exatamente o mesmo na HDL de cada espécie.
Uma evidência para a relação entre porção externa e interna na estrutura HDL, em répteis, foi pela observação de que a proteína e teor de ésteres de colesterol são significativamente correlacionados (Mills \& Taylaur, 1971).

Tabela 2. Médias da porcentagem do peso dos componentes de lipoproteínas plasmáticas de répteis e do homem

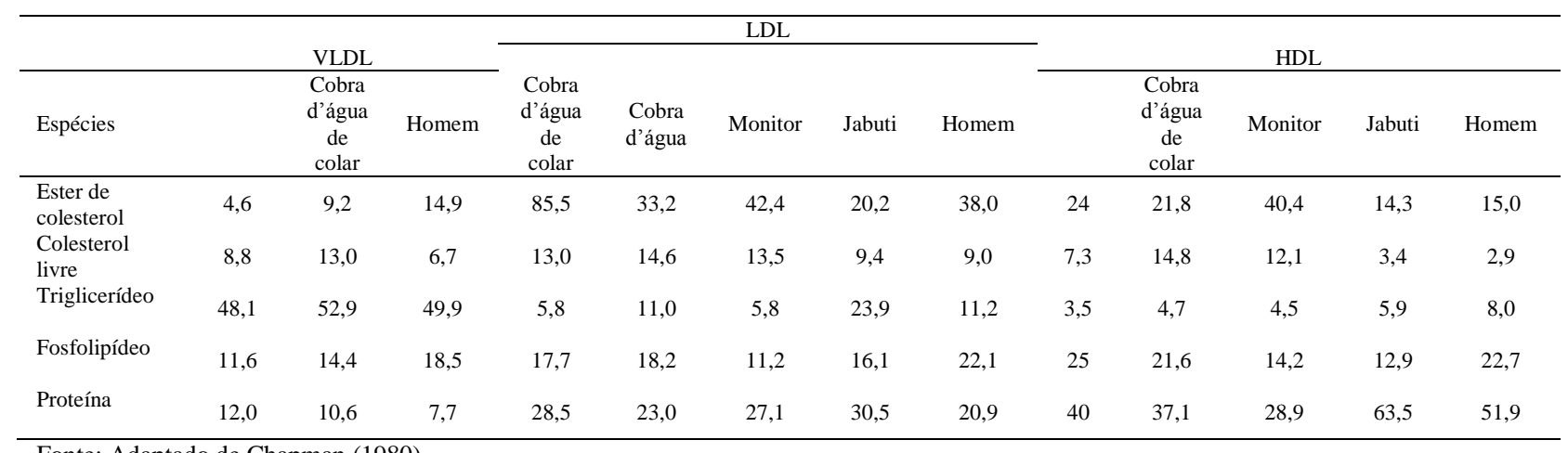

Fonte: Adaptado de Chapman (1980).

Os dados sobre as moléculas de proteínas de lipoproteínas do soro destes vertebrados ovíparos são bastante fragmentados. No entanto, evidências bioquímicas e imunológicas foram obtidas pela presença de uma contrapartida a apolipoproteína B humana na LDL de um réptil, a cobra rato (Ptyas mucosus) (Goldstein et al., 1977). Esta proteína de elevado peso molecular (>250.000) foi separada por filtração em cromatografia em gel, em solução de detergente, e foi encontrado um perfil de aminoácidos semelhante ao encontrado no homem, outros mamíferos, aves e peixes (Suzuki et al., 1977). A composição de aminoácidos do material correspondeu tipicamente a de apo-B em uma ampla variedade de vertebrados, rica em ácidos aspártico, glutâmico e leucina, e pobre em metionina, prolina e histidina. Estas observações de Suzuki et al. (1977) levantam a possibilidade que uma apo-B está presente em répteis (Goldstein et al., 1977).

Algumas investigações das lipoproteínas do soro de répteis são especialmente sujeitas a críticas, sob motivos que o sangue foi obtido de animais magros, Tabela 3 (Mills \& Taylaur, 1971; Suzuki et al. 1976; Mills, 1976; Dangerfield et al., 1976), e muitas vezes, apenas um exemplar de cada espécie foi estudado. As limitações de tal abordagem são bem ilustradas pelo estudo de Gillett \& Lima (1979), que claramente estabelece que há uma diminuição marcante no nível de colesterol sérico, com o aumento da idade e mudança na dieta do macho de calango (Tropidurus torquatus).

Tabela 3. Concentração de lipoproteínas no soro de répteis ${ }^{\mathrm{ab}}$ (Mills \& Taylaur, 1971).

\begin{tabular}{llllll}
\hline Espécie & VLDL & & LDL & HDL \\
& Sf 100-400 & Sf 20-100 & Sf 12-20 & Sf 0-12 & \\
\hline Natrix natrix & 149 & 58 & 48 & 359 & 382 \\
\hline Liopeltis vernalis & 0 & 64 & 92 & 1168 & N.D. \\
Natrix piscator & 84 & 213 & 211 & 267 & 222 \\
Ptyas mucosus & 0 & 43 & 111 & 320 & N.D. \\
Varanus salvator & 0 & 0 & 0 & 130 & 58 \\
Testudo graeca & 0 & 0 & 45 & 117 \\
\hline
\end{tabular}

${ }^{a}$ Concentrações são expressas em mg de lipoproteína/100 ml de soro; ${ }^{b}$ Distribuição determinada por ultracentrifugação; N.D., Não determinado;Fonte: Adaptado de Chapman (1980).

Tais achados sugerem que a idade e a dieta são fatores importantes na regulação da concentração de lipoproteínas por estes répteis. Diferenças marcantes também foram evidentes entre machos e fêmeas. São necessários trabalhos para avaliar se essas variações estão relacionadas com a vitelogênese no sexo feminino. O papel das lipoproteínas do soro em ovogênese em 
répteis tem sido negligenciado, mesmo apesar de serem vertebrados ovíparos.

\section{Quelônios}

Os quelônios surgiram há cerca de 200 milhões de anos, e tais animais compreendem os cágados, jabutis e tartarugas, existindo aproximadamente 290 espécies, 75 gêneros e 13 famílias (Cubas \& Baptistotte, 2006).

As gorduras são componentes essenciais ao metabolismo destes animais, havendo demanda das mesmas, mediante mobilização de depósitos endógenos em épocas de baixa oferta de alimento, conforme a sazonalidade ambiental natural na região de ocorrência da espécie. Grande demanda também decorre de épocas em que há a foliculogênese, ovogênese e ovipostura, quando fosfolipídeos em altas concentrações são essenciais para que esses processos ocorram dentro da normalidade e, portanto, possibilite um desempenho reprodutivo satisfatório às fêmeas.

Quanto às lipoproteínas, segundo Champman (1980), a tartaruga grega difere um pouco dos outros répteis, pois, embora possua uma moderada quantidade de HDL, e carência de VLDL, sua concentração de LDL é alta. Estudos adicionais, em outras espécies da mesma ordem (ou seja, Chelonia) são necessários para determinar se este tipo de perfil é comum a eles.

Perez et al. (2002) isolaram e purificaram a suposta apoproteína B-100, no plasma do quelônio Chrysemys picta, e determinaram que o peso molecular da mesma é aproximadamente $350 \mathrm{kDa}$. Os mesmos autores testaram o comportamento da apo B-100 com administração de estrogênio. $O$ tratamento com estrogênio administrado de forma aguda aumentou os níveis de apoproteínas B-100 (7,64 0,79 mg/ml de plasma), em comparação com o tratamento controle. Em contraste, o tratamento com administração de estrogênio de forma crônica reduziu o nível de apo B-100 significativamente $2,94 \pm 0,53 \mathrm{mg} / \mathrm{ml}$ no plasma $(\mathrm{P}<0,05)$. Demonstrando a influência hormonal sobre tais moléculas.

Cain et al. (2003) examinaram a composição dos lipídeos e apoproteínas de VLDL, IDL, LDL, HDL2 e HDL3 em tartaruga de orelha vermelha (Trachemys scripta elegans), em estado de jejum e alimentado. A composição lipídica de lipoproteínas deste animal foi muito semelhante aos homólogos humanos. A principal apolipoproteína encontrada no LDL, IDL e
VLDL, que tem um peso molecular de aproximadamente $550 \mathrm{kDa}$, e é um homólogo de apo B-100. Já a principal apolipoproteína encontrada em ambos os HDL2 e HDL3, tem um peso molecular de $28-\mathrm{kDa}$, e é homóloga à humana apo A-I. A HDL3 também contém uma proteína 6,5 $\mathrm{kDa}$ que é homóloga a apo A-II, enquanto HDL2 tem duas proteínas de baixo peso molecular, de 6 e $7 \mathrm{kDa}$, que também são encontradas no lipoproteínas ricas em triglicérides (TRL). A proteína $7 \mathrm{kDa}$ é homóloga a apoC-III, e a proteína $6 \mathrm{kD}$ tem um tamanho similar e distribuição a apoC-II ou apoC-I. Além disso, HDL2 possui também uma proteína de $15,8 \mathrm{kDa}$ que não tem óbvio homólogo em mamíferos. Em ambos, tamanho e composição de apoproteína, o HDL2 de tartaruga assemelha-se ao HDL2b humano, enquanto HDL3 de tartaruga também assemelha-se ao HDL3 humano. Em jejum, tartarugas continham muito pouco TRL. Quando alimentadas com uma dieta rica em gordura, as quantidades de IDL e LDL aumentaram significativamente.

\section{Crocodilianos}

Assim como em quelônios os lipídeos são de fundamental importância no metabolismo dos crocodilianos. Vários mecanismos neurológicos e endócrinos são susceptíveis a causar flutuações periódicas dos níveis de lipídios, principalmente colesterol (Coppo, 2001), um exemplo é que após a ingestão de alimentos, o soro de jacaré se torna hiperlipidêmico (Millan et al., 2007). Outro caso é a diminuição de lipídeos no inverno, registrada por Schoeb et al. (2002), que foi consistente com a depleção dos estoques de tecido adiposo efetuadas pelos répteis, na letargia causada pelo frio, por vezes, levando a estados de desnutrição. A maior parte dos valores obtidos em crocodilianos de zoológico foram superiores aos registrados na incubadora, reafirmando a noção de que a dieta afeta a concentração de lipídeos séricos (Gelman \& Morpurgo, 1994), e, portanto, também a composição da gordura corporal (Staton et al., 1990).

A grande variabilidade entre os valores adotados poderia ser atribuída as diferenças no tempo de coleta de sangue, local da punção venosa, o uso de plasma heparinizado em vez de soro, condições de jejum, o número de amostras desiguais, idade e sexo (Stacy \& Whitaker, 2000), além da época, de atrasos no processamento e da utilização de técnicas laboratoriais de análise (Coppo, 2001). 
Curiosamente, os valores de colesterol total de jacarés obtidos por alguns pesquisadores foram maiores em espécimes de vida livre (Ferreyra \& Uhart, 2001; Uhart et al., 2001), em contraste com os resultados que afirmam que tanto o colesterol total como triglicérides, fosfolipídios, ácidos graxos livres e lipídios totais foram maiores nos répteis em cativeiro, devido às mudanças na oferta de alimento (Lance et al., 2001).

Já Romanelli (1995) trabalhando com jacarédo-pantanal (Caiman yacare), observou valores de colesterol na carcaça de 60,53 a 85,48 $\mathrm{mg} / 100 \mathrm{~g}$. E Vicente Neto (2005) verificou 51,23 $\mathrm{mg} / 100 \mathrm{~g}$ para animais de cativeiro e 38,83 $\mathrm{mg} / 100 \mathrm{~g}$ para animais de vida-livre. Tal diferença provavelmente se deu por conta da alimentação diferenciada nos dois locais, já que em cativeiro a alimentação dos animais foi rica em ácidos graxos saturados e colesterol. Corroborando a afirmação de Lance et al. (2001).

Os valores de lipídeos podem ser ferramentas importantes para avaliar o estado de saúde dos crocodilianos. Seu papel é altamente energético, sendo importantes como componentes de tecidos e secreções. Os ácidos graxos livres são uma fonte de energia para os tecidos, especialmente os músculos, cobrindo até $60-70 \%$ das necessidades energéticas do miocárdio. $\mathrm{O}$ colesterol está envolvido na síntese de ácidos biliares, surfactante pulmonar, vitamina D, hormônios gonadais e adrenais (Coppo, 2001). A partir da esterificação do colesterol com ácidos graxos de cadeia longa, os crocodilos sintetizam uma substância utilizada para a marcação do ninho e atração do casal, secretada pelas glândulas paracloacais (Yang et al., 1999), também de fundamental importância para a espécie.

Segundo Barboza et al. (2008), em animais da espécie jacaré-de-papo-amarelo (Caiman latirostris), em cativeiro, o colesterol total, LDLC, HDL-C e lipoproteínas beta foram significativamente mais baixos na estação fria, que na estação quente, na Argentina. Tourn et al. (1994) também verificaram variações estacionais nos níveis de HDL-C e LDL-C em fêmeas de jacaré-de-papo-amarelo nascidas e criadas em cativeiro (Tabela 4). Demonstrando a sazonalidade destes compostos, fato que deve ser levado em consideração em pesquisas e manejos dos animais em questão. Inclusive, podendo o excesso de lipídeos afetar negativamente a função reprodutiva dos crocodilianos (Lance et al., 2001). Barboza et al. (2008) também compararam espécimes de jacaré-de-papoamarelo dos diferentes sexos observaram que só houve diferença nas lipoproteínas beta, que apresentaram-se superiores nas fêmeas. Outros parâmetros do lipidograma (colesterol total, triglicerídeos, LDL-C e lipoproteínas alfa) foram mais altos nos machos, enquanto o HDL-C não apresentou diferença intersexual (Tabela 5). Portanto, deve-se considerar o sexo do animal nas análises de lipoproteínas em crocodilianos.

Tabela 4. Variação dos parâmetros bioquímicos do soro de jacaré-de-papo-amarelo (Caiman latirostris), segundo estações sazonais.

\begin{tabular}{lcccc}
\hline \multirow{2}{*}{ Parâmetro } & \multicolumn{2}{c}{ Estação quente } & \multicolumn{2}{c}{ Estação fria } \\
& $\mathrm{X} \pm \mathrm{DP}$ & $\mathrm{IC} \pm 95 \%$ & $\mathrm{X} \pm \mathrm{DP}$ & $\mathrm{IC} \pm 95 \%$ \\
\hline Triglicerídeos $(\mathrm{g} / \mathrm{l})$ & $0,34 \pm 0,20^{\mathrm{a}}$ & $0,27-0,41$ & $0,26 \pm 0,13^{\mathrm{a}}$ & $0,22-0,31$ \\
Colesterol total $(\mathrm{g} / \mathrm{l})$ & $0,33 \pm 0,16^{\mathrm{a}}$ & $0,29-0,37$ & $0,24 \pm 0,13^{\mathrm{b}}$ & $0,20-0,29$ \\
Colesterol - HDL $(\mathrm{g} / \mathrm{l})$ & $0,03 \pm 0,01^{\mathrm{a}}$ & $0,02-0,04$ & $0,02 \pm 0,01^{\mathrm{b}}$ & $0,01-0,03$ \\
Colesterol- LDL $(\mathrm{g} / \mathrm{l})$ & $0,11 \pm 0,08^{\mathrm{a}}$ & $0,09-0,13$ & $0,15 \pm 0,08^{\mathrm{b}}$ & $0,12-0,18$ \\
Lipoproteínas alfa (\%) & $81,62 \pm 6,02^{\mathrm{a}}$ & $79,96-83,28$ & $87,92 \pm 5,04^{\mathrm{b}}$ & $85,79-90,05$ \\
Lipoproteínas beta (\%) & $18,38 \pm 6,02^{\mathrm{a}}$ & $16,72-20,04$ & $12,08 \pm 5,04^{\mathrm{b}}$ & $9,95-14,21$ \\
\hline
\end{tabular}

Fonte: Adaptado de Barboza et al. (2008)

Em machos de jacaré americano (Alligator mississippiensis), Lance \& Lauren (1984) observaram valores de colesterol total inferiores aos obtidos por Barboza et al. (2008), tanto para espécimes em vida livre $(0,01 \mathrm{~g} / \mathrm{l})$ (Lance et al., 1983), como criados em cativeiro $(0,005 \mathrm{~g} / \mathrm{l})$ ( Lance \& Lauren, 1984). Em um macho de 7,5 kg de peso vivo e duas fêmeas (de 5 e $7 \mathrm{~kg}$ ) de jacaré-coroa (Paleosuchus trigonatus), espécie pertencente à mesma subfamília do aligator americano e do jacaré-de-papo-amarelo, se registraram valores mais altos $(0,56 ; 0,66$; $0,35 \mathrm{~g} / \mathrm{l}$, respectivamente) (Rojas \& Chaves, 2005). 
Barboza et al. (2008) também observaram que os valores de colesterol total, triglicérides, HDL$\mathrm{C}$ e lipoproteínas beta aumentaram com o peso, porém lipoproteínas alfa e LDL-C apresentaram diminuição significativa nos níveis à medida que a idade avançava (Tabela 6). Em exemplares de crocodilo-persa (Crocodylus palustris) observou- se um aumento do colesterol total em juvenis e sub-adultos, em comparação com indivíduos adultos, porém os valores de triglicerídeos foram mais baixos em sub-adultos e mais altos em juvenis (Stacy \& Whitaker, 2000). Evidenciando a idade como outro fator de importância nas análises de lipoproteínas em crocodilianos.

Tabela 5. Variação dos parâmetros bioquímicos do soro de jacaré-de-papo-amarelo (Caiman latirostris), segundo o sexo dos animais.

\begin{tabular}{lcccc}
\hline \multicolumn{1}{c}{ Parâmetro } & \multicolumn{2}{c}{ Machos } & \multicolumn{2}{c}{ Fêmeas } \\
& $\mathrm{X} \pm \mathrm{DP}$ & $\mathrm{IC} \pm 95 \%$ & $\mathrm{X} \pm \mathrm{DP}$ & $\mathrm{IC} \pm 95 \%$ \\
\hline Triglicerídeos $(\mathrm{g} / \mathrm{l})$ & $0,38 \pm 0,16^{\mathrm{a}}$ & $0,25-0,50$ & $0,29 \pm 0,17^{\mathrm{a}}$ & $0,25-0,33$ \\
Colesterol total $(\mathrm{g} / \mathrm{l})$ & $0,31 \pm 0,14^{\mathrm{a}}$ & $0,20-0,41$ & $0,28 \pm 0,15^{\mathrm{a}}$ & $0,25-0,32$ \\
Colesterol - HDL $(\mathrm{g} / \mathrm{l})$ & $0,02 \pm 0,01^{\mathrm{a}}$ & $0,01-0,03$ & $0,02 \pm 0,01^{\mathrm{a}}$ & $0,02-0,03$ \\
Colesterol- LDL $(\mathrm{g} / \mathrm{l})$ & $0,14 \pm 0,01^{\mathrm{a}}$ & $0,09-0,20$ & $0,11 \pm 0,08^{\mathrm{a}}$ & $0,09-0,13$ \\
Lipoproteínas alfa $(\%)$ & $86,30 \pm 5,03^{\mathrm{a}}$ & $82,09-90,51$ & $84,72 \pm 5,06^{\mathrm{a}}$ & $83,04-86,04$ \\
Lipoproteínas beta (\%) & $13,70 \pm 5,03^{\mathrm{a}}$ & $9,49-17,91$ & $15,28 \pm 5,06^{\mathrm{a}}$ & $13,96-16,60$ \\
\hline
\end{tabular}

Fonte: Adaptado de Barboza et al. (2008).

Coppo et al. (2007) estudaram durante dois anos 223 jacarés, 50\% de Caiman latirostris e $50 \%$ Caiman yacare, sendo metade de cada sexo, com idades de 1 - 5 anos, pesos de $2-7 \mathrm{~kg}$ e comprimento de $80-130 \mathrm{~cm}$, submetidos a distintos sistemas de alimentação e manejo. E obtiveram valores séricos apresentados na Tabela 7 para as espécies estudadas

Tabela 6. Variação dos parâmetros bioquímicos do soro de jacaré-de-papo-amarelo (Caiman latirostris), segundo a idade.

\begin{tabular}{lccc}
\hline Parâmetros & Idade 1 & Idade 2 & Idade 3 \\
\hline Triglicerídeos $(\mathrm{g} / \mathrm{l})$ & $0,24^{\mathrm{a}}$ & $0,31^{\mathrm{a}}$ & $0,31^{\mathrm{a}}$ \\
Colesterol total $(\mathrm{g} / \mathrm{l})$ & $0,29^{\mathrm{a}}$ & $0,29^{\mathrm{a}}$ & $0,31^{\mathrm{a}}$ \\
Colesterol - HDL $(\mathrm{g} / \mathrm{l})$ & $0,02^{\mathrm{a}}$ & $0,02^{\mathrm{a}}$ & $0,03^{\mathrm{a}}$ \\
Colesterol- LDL $(\mathrm{g} / \mathrm{l})$ & $0,14^{\mathrm{a}}$ & $0,13^{\mathrm{b}}$ & $0,09^{\mathrm{c}}$ \\
Lipoproteínas alfa (\%) & $84,65^{\mathrm{a}}$ & $83,98^{\mathrm{a}}$ & $81,73^{\mathrm{a}}$ \\
Lipoproteínas beta (\%) & $15,35^{\mathrm{a}}$ & $16,02^{\mathrm{a}}$ & $18,27^{\mathrm{a}}$ \\
\hline
\end{tabular}

Fonte: Adaptado de Barboza et al. (2008).

Os valores de colesterol total apresentaram-se significativamente mais altos em $C$. latirostris que em $C$. yacare. Para o conjunto de ambas as espécies, o mesmo foi significativamente mais baixo em fêmeas que em machos. Considerando os grupos de idade, observaram que o peso foi negativamente correlacionado com níveis de colesterol total $(r=-0,91)$, triglicérides $(r=-$ $0,94)$, HDL-C $(r=-0,87)$, LDL-C $(r=-0,84)$ e da lipoproteína alfa $(\mathrm{r}=-0,89)$ e positivamente com a beta-lipoproteína $(\mathrm{r}=0,90)$. O comprimento total aumentou linearmente também associado com elevações destas variáveis lipídicas. E que houve correlação significativa entre os níveis plasmáticos de triglicerídeos e colesterol total $(\mathrm{r}$ $=0,88)$ entre as lipoproteínas HDL-C e alfa $(r=$ $0,94)$ e entre LDL-C e beta-lipoproteínas $(r=-0$, 93).

Tabela 7. Valores séricos de colesterol, triglicerídeos e lipoproteínas para C. latirostris e C. yacare.

\begin{tabular}{lll}
\hline & C. latirostris & C. yacare \\
\hline Colesterol total $(\mathrm{g} / \mathrm{I})$ & $0,31 \pm 0,12$ & $0,47 \pm 0,13$ \\
Triglicerídeos $(\mathrm{g} / \mathrm{I})$ & $0,47 \pm 0,13$ & $0,50 \pm 0,14$ \\
C-HDL $(\mathrm{g} / \mathrm{I})$ & $0,04 \pm 0,01$ & $0,06 \pm 0,02$ \\
C-LDL $(\mathrm{g} / \mathrm{I})$ & $0,19 \pm 0,06$ & $0,22 \pm 0,08$ \\
Lipoproteína alfa $(\%)$ & $82,8 \pm 6,9$ & $82,3 \pm 7,2$ \\
Lipoproteína beta $(\%)$ & $17,2 \pm 4,1$ & $17,7 \pm 3,3$ \\
\hline
\end{tabular}

Fonte: Coppo et al. (2007) 


\section{Lagartos}

Os sáurios ou lagartos, como são popularmente conhecidos, constituem o grupo com as características mais variadas dentro da classe Reptilia. Compreendem desde os minúsculos gecos aos gigantes dragões-deKomodo (Goulard, 2006).

Neste grupo sabe-se que a ultracentrifugação analítica (em um solvente de densidade 1,063 $\mathrm{g} / \mathrm{ml}$ ) sugere que o varano malaio (Varanus salvator) apresenta uma distribuição essencialmente contínua de lipoproteínas, que é seccionada pelo limite de 1,063 g/ml (Mills \& Taylaur, 1971). Observa-se, portanto, que no varano malaio não pode haver apenas uma única classe de lipoproteínas, como Mills \& Taylaur (1971) sugeriram a partir da similaridade na composição do "LDL" e "HDL" deste ectotérmico. Alternativamente, este resultado pode ser explicado pela presença na "fração HDL" de uma grande proporção de partículas de LDL, e uma pequena quantidade de verdadeiras lipoproteínas de alta densidade, uma situação caracterizada pela cobaia, cujas apo-B, lipoproteínas de baixa densidade são distribuídas até uma densidade de $1,100 \mathrm{~g} / \mathrm{ml}$ e que possuem concentrações de HDL de $10 \mathrm{mg} / 100 \mathrm{ml}$ ou menos no soro (Puppione et al., 1971; Champman \& Mills, 1977).

Baixa quantidade de proteína e alto conteúdo de éster colesterol $(28,9$ e $40,4 \%$, respectivamente) do total de "HDL" do varano sugerem que a sua predominância se assemelha a uma espécie de LDL, mais do que um verdadeiro HDL. A natureza geral do perfil de lipoproteína de répteis, (isto é, concentrações relativamente elevadas de LDL e HDL nos répteis, predominando LDL), foi confirmada em outros estudos em que procedimentos menos precisos têm sido empregados para a quantificação, como eletroforese em gel de agarose ou outros meios (Alexander \& Day, 1973; Dangerfield et al., 1976).

O Uromastix hardwickii, um lagarto hibernador, sofre alterações sazonais nos hábitos alimentares e atividades físicas. As variações sazonais nas lipoproteínas plasmáticas, colesterol e proteínas plasmáticas totais foram estudadas neste réptil por Jamall et al. (2003), os quais observaram que a concentração de proteína plasmática total permaneceu inalterada durante períodos ativos e de hibernação $(5,30 \pm 1,42$ e $5,38 \pm 1,14 \mathrm{~g} / \mathrm{dl}, \quad$ respectivamente), diminuiu ligeiramente durante o período de excitação $(4,90 \pm 0,84 \mathrm{~g} / \mathrm{dl})$ e aumentou significativamente durante o período preparativo $(6,49 \pm 1,09 \mathrm{~g} / \mathrm{dl})$. Variações sazonais significativas ocorreram na concentração plasmática de colesterol total que diminuiu significativamente durante o período de excitação $(226 \pm 104 \mathrm{mg} / \mathrm{dl})$ e aumentou significativamente durante o período de préhibernação $\quad(457 \pm 134 \quad \mathrm{mg} / \mathrm{dl})$. O Uromastix hardwickii teve níveis plasmáticos significativamente mais baixos de colesterol total $(250 \pm 110 \mathrm{mg} / \mathrm{dl})$ no período de hibernação, do que no período ativo $(348 \pm 117 \mathrm{mg} / \mathrm{dl})$. Apenas duas classes de lipoproteínas LDL e HDL foram detectadas neste réptil, e o LDL foi a classe predominante. A proporção relativa das LDL: HDL foi baixa $(57,1: 42,9)$ durante o período de preparação. Aumentou para 70,9: 29,1 durante a hibernação e para 73,5:26,5 durante o período de excitação. Não foi observada diferença significativa nos índices médios da relação LDL: HDL durante a hibernação e períodos de excitação. Durante o período ativo, a média da razão LDL: HDL foi de 72,3:27,7, com máxima de85,7: 14,3.

\section{Ofídios}

Concentrações de HDL semelhantes às do homem foram observadas em serpentes. Esses répteis apresentam elevadas concentrações de LDL de Sf 0-20, e também, ocasionalmente, de VLDL. Nos répteis, os níveis de LDL são altos Sf 0-12 LDL (entre 407-1260 mg/100 ml) de forma a ultrapassar as do homem (Mills \& Taylaur, 1971; Nichous, 1967), tornando-os quase único no reino animal. O padrão de ácidos graxos de éster colesterol do LDL de cobra d'água foi altamente insaturado, aparentemente desprovido de qualquer ácido graxo saturado e é rico em ácido araquidônico (50\%) e linoléico (27\%). A serpente d'água, portanto, parece mais estreitamente relacionada com os peixes, por possuir teor de ácidos graxos insaturados de cadeia longa. Os ésteres de colesterol das lipoproteínas de cobra d'água, portanto, parecem possuir uma composição intermediária entre os dos peixes e os vertebrados superiores, ou seja, as aves e mamíferos. Se o padrão de ácido graxo e de colesterol éster em répteis resulta a partir da especificidade LCAT dessas espécies, ou se é uma função direta da composição de ácidos graxos de sua lecitina como substrato, como sugerido por Gillett (1978), ainda não se sabe. Alguma semelhança foi vista no padrão de ácidos 
graxos dos triglicerídeos de lipoproteínas rã-touro e cobra d'água, no caso do oléico, que foi, como no homem, o componente principal (Chapman, 1980).

A semelhança entre os triacilgliceróis humanos e répteis também se estendeu à presença de moderado a altos níveis de ácido palmítico e linoléico. O modesto nível de ácido araquidônico foi detectado nos triacilgliceróis de serpente (LDL), uma proporção substancialmente maior do presente ácido estava em seus fosfolipídios, na verdade, era o principal componente (34\%). Grandes quantidades de ácidos graxos 18:0, 18:1 e 18:2 (17-20\%) também foram encontrados nos fosfolipídeos de cobra, uma característica comum aos seus homólogos humanos (Suzuki et al., 1976). A cobra d'água parece ter conservado mais as propriedades típicas de lipídios de peixes que os anfíbios (Tabela 8), mas se isso resulta da ingestão de ácidos graxos alimentares ou é o reflexo de uma exigência estrutural ainda necessita ser avaliado (Chapman, 1980).

Janeiro-Cinquini et al. (1995) analisaram o plasma de machos de Bothrops jararaca tratados com estrogênio e observaram frações de muito baixa densidade, densidade intermediária e alta densidade, respectivamente. A microscopia eletrônica das lipoproteínas de densidade muito baixa mostra uma única população de partículas com um diâmetro médio de 29,6 nm, semelhante a VLDL de galinhas poedeiras. As VLDLs de Bothrops jararaca é composta por dois polipeptídeos com massas moleculares de 450 e $20 \mathrm{kDa}$. Três polipeptídeos principais foram detectados na fração de plasma de alta densidade, com massas moleculares de 190, 160 e $110 \mathrm{kDa}$. Análise de proteínas do plasma, dos animais controle e machos tratados com estrogênio, mostrou que os polipeptídeos de $20 \mathrm{kDa}$ na lipoproteína de muito baixa densidade e os polipeptídeos de 160 e 110 kDa em lipoproteína de alta densidade são induzidas novamente, após tratamento com estrogênio. Estes resultados sugerem que os dois polipeptídeos das lipoproteínas de muito baixa densidade são homólogos, nas cobras, dos polipeptídeos de densidade muito baixa em frangos. $O$ estrogênio induziu polipeptídeos de lipoproteína de alta densidade, que provavelmente compõem a vitelogenina de Bothrops jararaca. Um anti-soro produzido contra toda fração de plasma de muito baixa densidade de plasma foi capaz de reconhecer apenas os dois polipeptídeos encontrados nesta fração do plasma dos animais do sexo masculino tratados. Usando esse antisoro foi capaz de detectar apenas uma reação fraca contra proteínas de gema de ovo de Bothrops jararaca.

Tabela 8. Composição lipídica de LDL de cobra d'água (Natrix piscator) (Mills \& Taylaur, 1971).

\begin{tabular}{|c|c|c|c|c|c|c|c|c|c|c|c|c|}
\hline Lipídeo & $14: 0$ & 16:0 & $16: 1$ & 18:0 & $18: 1$ & $18: 2$ & $18: 3$ & $20: 0$ & $20: 1$ & $20: 4$ & $22: 0$ & $24: 1$ \\
\hline $\begin{array}{l}\text { Éster de } \\
\text { colesterol }\end{array}$ & & & & & 19,7 & 27,1 & & & 4,8 & 1,8 & & \\
\hline Fosfolipídeo & & 5,0 & & 17,0 & 20,0 & 18,0 & & & & 1,4 & & \\
\hline
\end{tabular}

Fonte: Adaptado de Chapman (1980).

Vale ressaltar que o papel de ésteres de colesterol das lipoproteínas dos répteis parecem não ter função no transporte dos ácidos graxos essenciais, eicosapentanóico e docosahexanóico. Porém, tais dados foram observados a partir de estudos de apenas uma única espécie de réptil, e deve ser realizado para outros membros dessa classe de vertebrados antes que mais conclusões gerais possam ser extraídas (Chapman, 1980).

\section{Distúrbios no metabolismo de lipídeos em répteis}

Répteis possuem, na natureza, alimentação intermitente. Como apresentam baixa necessidade calórica, por serem ectotérmicos, se alimentados regularmente em cativeiro tendem a desenvolver obesidade. Esta condição está associada à uma menor tolerância a temperaturas elevadas, aumento da incidência de infecções, infertilidade em machos e à lipidose hepática. A obesidade tem sido relatada em várias espécies, como iguana (Iguana iguana) e teiús (Tupinambis sp.) (Vienet, 2000; Frye, 1991).

Segundo Frye (1986), os jacarés mantidos em cativeiro geralmente consomem dietas ricas em ácido graxos saturados, sendo frequentes as esteatoses, deficiências de vitamina E, e obesidade, além de transtornos reprodutivos. Os parâmetros lipídicos do plasma geralmente são mais altos em animais de cativeiro que em vidalivre (Lance et al., 2001). Diferente das dietas oferecidas nos criatórios, as presas que o animal 
captura em vida-livre possuem níveis adequados de lipídeos, aminoácidos essenciais, vitaminas, minerais, etc., o que sugere análises hematológicas.

A lipidose ou esteatose hepática também já foi diagnosticada em outros répteis, como a iguana e o jaboti. Nesta patologia há uma alteração na metabolização dos lipídeos no fígado, fazendo com que o fígado do animal adquira um aspecto tumefeito, coloração amarela e flutue na água. Esta patologia é fatal para os répteis, e atinge principalmente animais de cativeiro, devido alimentação em excesso ou alimentação insuficiente, que pode causar inanição, e falta de exercício. Esta patologia pode evoluir para uma forma crônica, a cirrose hepática (Echeto \& Aranjinbel, 1999).

Lance \& Elsey (1999) estudaram as alterações de triglicérides e colesterol de jacarés. Patologicamente, lipídios são elevados em hipotireoidismo, diabetes, doenças renais, pancreatite e icterícia obstrutiva, cálculos biliares. E podem causar diminuição o hipertireoidismo, insuficiência renal (com éster de colesterol diminuído) e os estados de má absorção ou de desnutrição. As deficiências nutricionais e ao esgotamento das reservas leva a hipolipemia (Coppo, 2001).

Os principais metabólitos que indicam a variação no metabolismo lipídico são colesterol total, triglicerídeos e lipoproteínas de baixa e alta densidade. Grummer \& Carrol (1988) propuseram um modelo para explicar como uma dieta lipídica pode alterar a esteroidogênese ovariana. Acreditavam na possibilidade de interferência na função ovárica cíclica por via das modificações nas dietas. Essas dietas alterariam o nível do principal substrato, possivelmente o colesterol, sendo que o uso de hormônios ou fármacos específicos permitiria o aumento da internalização dos substratos esteroidais.

Distúrbios reprodutivos também são relatados como resultantes de alterações no metabolismo de lipídeos. Poucos trabalhos consideram a importância do metabolismo específico como o do colesterol, a rota do metabolismo das lipoproteínas ou receptores de lipoproteínas na mediação da função luteal normal ou alterada. Sendo muito importante lembrar que a progesterona é sintetizada a partir do colesterol que é derivado, em grande parte, de um "pool" de lipoproteínas conjugadas com colesterol (Gwynne \& Strauss, 1982).

\section{Considerações finais}

As características das lipoproteínas em répteis variam, de acordo com a ordem e espécie animal, porém em todas as espécies observam-se certa similaridade com as lipoproteínas humanas, inclusive a presença de homólogos de várias apoproteínas humanas. Porém, as informações sobre esse complexo molecular ainda são escassas, quando se pensa na grande diversidade da classe Reptilia, necessitando assim de mais estudos, principalmente com os répteis submetidos à alimentação oferecida pelo homem, como os animais de finalidade produtiva e os de zoológicos.

\section{Referências bibliográficas}

Alexander, C. \& Day, C. E. Distribution of serum lipoproteins of selected vertebrates. Comp. Biochem. Physiol., v. 46B, p. 295-312, 1973.

Barboza, N. N.; Mussart, N. B.; Coppo, J.A.; Fioranelli, S. A.; Koza, G. A. El medio interno de Caiman latirostris en cautiverio: Influencia del sexo, crecimiento y estación del año. Rev. vet., v. 19, n. 1, p. 33-41, 2008.

Cain, W.; Song, L.; Stephens, G.; Usher, D. Characterization of lipoproteins from the turtle, Trachemys scripta elegans, in fasted and fed states. Comparative Biochemistry and Physiology Part A. n. 134, p. 783-794, 2003.

Champe, P. C.; Harvey, R. A.; Ferrier, D. R. Bioquímica Ilustrada. $3^{\text {a }}$ ed. Ed. Artmed. Porto Alegre, RS, 2006, 544p.

Chapman, M. J. \& Mills, G. L. Characterization of the serum lipoproteins and their apoproteins in hypercholesterolemic guinea pigs. J. Biochem., n. 167, p. 9-21, 1977.

Chapman, M. J. Animal lipoproteins: chemistry, structure, and comparative aspects. Journal of Lipid Research., v. 21, p. 789- 844, 1980.

Coppo, J. A. Fisiología Comparada del Medio Interno, Ed. Dunken, Buenos Aires, p.212216, 2001.

Coppo, J. A. Fundamentos y Metodología de la Investigación Científica, Ed. Moglia, Corrientes, tomo II, p. 241-251, 2005.

Coppo, J. A.; Mussart, N. B.; Barboza, N. N. Cambios fisiológicos del lipidograma sérico durante el cautiverio de caimanes del nordeste argentino (C. latirostris y $C$. yacare). Vet. Arg., v. 24, n. 232, p. 101-112, 2007. 
Crawford, M. A.; Stevens, P.; Williams, G. \& Turner, R. W. D. Dietary fats and heart disease. Progress in Lipid Research, Oxford, v. 20, p. 589-593, 1981.

Cubas, P. H. \& Baptistotte, C. Chelonia (tartaruga, cágado e jabuti). In: Cubas, Z. S.; Silva, J. C. R \& Catão-Dias, J. L. Tratado de animais selvagens. Ed. Roca, São Paulo, 2006, 1354 p.

Dangerfield, W. G.; Finlayson, R.; Myatt, G. \& Mead, M. G. Serum lipoproteins and atherosclerosis in animals. Atherosclerosis, n. 25, p. 95- 106, 1976.

Echeto, O. E. V.; Aranjinbel, C. Lipidosis hepática y cirrosis em morrocoy (Geochelone carbonaria): Descripción de um caso. Revista Científica, FCV- Luz, v. 9, n. 6, p. 469-476, 1999.

Ferreyra, H. \& Uhart, M. Evaluación y evolución del estado sanitario de Caiman latirostris y Caiman yacare en el Refugio El Cachapé. Boletín Técnico de la Fundación Vida Silvestre Argentina 55, Anexo 11, n. 1, p. 115, 2001.

Fontes, R. Origem, transporte e destino dos lipídeos do plasma I. Disponível em: http://users.med.up.pt/ruifonte/PDFs/20052006/G14_Lipoproteinas_plasmaticas_I.pdf. Acesso em: 15/09/2009.

Frye, F. L. A Practical Guide for Feeding Captive Reptiles. Malabar FL: Krieger Publishing Company, 1991.

Frye, F. L. Hematology of Captive Reptiles. In: Zoo and Wild Animal Medicine (Fowler EM Ed.), $2^{\circ}$ ed., Saunders, Philadelphia, p. 181184, 1986.

Frye, F. L. Hepatic Disorders. Reptile care. An atlas of Diseases and Treatments. Edit. TFH Publications INC. New Jersey, v. 2, p. 545547, 1991.

Gelman, A.; Morpurgo, B. The effect of diet on the plasma cholesterol and plasma fatty acids levels of the Nile crocodile Crocodylus niloticus. Isr J Zool , n. 40, p. 94-96, 1994.

Gillett, M. P. T. \& Lima, V. L. M. Marked decrease in plasma cholesterol concentration with increasing age in male lizards. Atherosclerosis, n. 32, p. 461 - 463, 1979.

Gillett, M. P. T. Comparative studies of the lecithin: cholesterol acyltransferase reaction in the plasma of reptiles and amphibians. Scand. J. Clin. Lab. Invest, 38, SUPPI. 150: p. 32-39, 1978.

Goldstein, S.; Chapman, M. J.; Mills, G. L. Biochemical and immunological evidence for the presence of an apolipoprotein B-like component in the serum low density lipoproteins of several animal species. Atherosclerosis, n. 28 p. 93- 100, 1977.

Goulard, C. E. S. Ordem Squamata- Subordem Sáuria. In: Cubas, Z. S.; Silva, J. C. R; CatãoDias, J. L. Tratado de animais selvagens. Ed. Roca, São Paulo, 2006, 1354 p.

Grummer, R. R. \& Carroll. A review of lipoprotein cholesterol metabolism importance to ovarian function. J. Anim. Sci., v. 6, p. 3160-3173, 1988.

Gwynne, J. T. \& Straus, J. F. The role of lipoprotein in steroidogenesis and cholesterol metabolism steroidogenic glands. Endocr. Rev., v. 3, p.299-304, 1982.

Jamall, S.; Siddiqui, A. A. \& Ishaq, M. Seasonal variations in total plasma protein, cholesterol and lipoproteins, in Uromastix hardwickii. Animal physiology and biochemistry, v. 36, n. 1, p. 45-52, março, 2003.

Janeiro-Cinquini, T. R. F.; Bijovsky, A. T.; Leinz, F. F. \& Wintert, C. E. Characterization of the main plasma from the ovoviviparous viperid snake Bothrops jararaca lipoproteins. Comp. Biochem. Physiol., v. 112B, n. 1, p. 49-58, 1995.

Kane, J. P. Plasma lipoproteins: structure and metabolism. In: Lipid Metabolism in Mammals. V. 1. F. Snyder, editor. Plenum Press, New York, p. 209-257, 1978.

Lance, V. A. \& Elsey, R. M. Plasma catecholamines and plasma corticosterone following restraint stress in juvenile alligators. J Exp Zool, n. 283, p. 559-565, 1999.

Lance, V. A. \& Lauren, D. Circadian variation in plasma corticosterone in the american alligator, Alligator mississippiensis, and the effect of ACTH injections. Gen. Comp. Endocrinol., n. 54, p. 1-7, 1984.

Lance, V. A.; Mprici, L. A., Elsey, R. M.; Lund, E. D. \& Place, A. R. Hyperlipidemia and reproductive failure in captive-reared alligators: vitamin $\mathrm{E}$, vitamin $\mathrm{A}$, plasma lipids, fatty acids, and steroid hormones. 
Comp. Biochem. Physiol. 128: p. 285-294, 2001.

Mayes, P. A. Transporte e armazenamento de lipídeos. In: Murray, R. K.; Granner, D. K.; Mayes, P. A.; Rodwell, V. W. Harper:

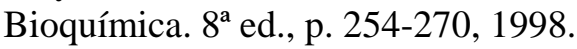

Millan, J. M.; Janmmat, A.; Richardson, K. C.; Chambers, L. K. \& FormiattiI, K.R. Reference ranges for biochemical and haematological values in farmed saltwater crocodile (Crocodylus porosus) yearlings. Aust Vet J, v. 75, p. 814-817, 1997.

Mills, G. L. \& Taylaur, C. E. The distribution and compositions of serum lipoproteins in eighteen animals. Comp. Biochem. Physiol., v. 40B, p. 489-501, 1971.

Mills, G. L. Lipoproteins in animals. In: Handbuch der Inneren Medizin, Band VIU4 Fettstoffwechsel. G. Schettler, H. Greten, G. Schlierf, and D. Seidel, editors. SpringerVerlag, Berlin. p. 173- 195, 1976.

Murray, R. K.; Granner, D. K.; Mayes, P. A. \& Rodwell, V. W. Harper's Illustrated Biochemistry. 26a ed., 2003, 703p.

Nelson, D. L.; COX, M. M. \& Lehninger Principles of Biochemistry. $4^{\mathrm{a}}$ ed., 1119p. 2005.

Nichols, A. V. Human serum lipoproteins and their interrelationships. Adv. Biol. Med. Phys. v. 11, p. 109-158, 1967.

Perez, L. E.; Williams, D. \& Callard, I. P. Putative apolipoprotein B-100 in the freshwater turtle Chrysemys picta: effects of estrogen and progesterone. Comparative Biochemistry and Physiology Part B: Biochemistry and Molecular Biology, v. 103, n. 3, p. 707-713, November, 1992.

Puppione, D. L.; Sardet C.; Yamanaka, W; Ostwald, R. \& A. V. Nichols. Plasma lipoproteins of cholesterol-fed guinea pigs. Biochim. Biophys. Acta. v. 23, n. 1, 295-301, 1971.

Rodrigues, M. T. Conservação dos répteis brasileiros: os desafios de um país megadiverso. Megadiversidade, v. 1, n. 1, p. 87-94, Julho, 2005.

Rojas, M. G. \& Cháves, I. G. Valores bioquímicos séricos de caimán frente lisa (Paleosuchus trigonatus) mantenidos en cautiverio en Perú. Proceedings de la Reunión
Regional de América Latina y el Caribe del CSG/SSC/ IUCN (Santa Fe, Argentina), p. 261-266, 2005.

Romanelli, P. F. Propriedades tecnológicas da carne do jacaré do pantanal Caiman crocodilus yacare (Daudin, 1902). 1995, 110p. Tese (Doutorado em Tecnologia de Alimentos) Universidade de Campinas Campinas - SP.

Schoeb, T. R.; Heaton-Dones, T. G. \& Clemmons, R. M.. Clinical and necropsy findings associated with increased mortality among american alligators of Lake Griffin, Florida. J Wildl Dis, n. 38, p. 320-337, 2002.

Sinclair, A. J. \& O'Dea, K. Fats in Human diets through history: is the western diet out of step? In: WOOD, J. D.; FISHER, A. V. Reducing fat in meat animals. London: Elsevier, p. 1-47, 1990.

Stacy, B. A. \& Whitaker, N. Hematology and blood biochemistry of captive mugger crocodiles (Crocodylus palustris). J Zoo Wildl Med. n. 31, p. 339-347, 2000.

Station, M. A.; Edwards, H. M. \& Brisbin. Essential fatty acid nutrition of the American ailigator, Alligator mississippiensis. J Nutr, $n$. 120, p. 674-685, 1990.

Suzuki, N.; Deguchi, K. \&; Ueta N.. Chemical characterization of the serum very low density and high density lipoproteins from bullfrog, Rana catesbeiana. J. Biochem. n. 80, p. 1241 - 1246, 1976.

Suzuki, N.; Kawashima S. \& Fukushima, S. Isolation and partial characterization of the serum low density lipoprotein from bullfrog, Rana catesbaiana. J. Biochem. n. 81: p. 1231 - 1236, 1977.

Uhart, M.; Prado, W. \& Beldoménico. Estudios sanitarios comparativos de yacarés (Calman latirostris y Caiman yacaré) silvestres y cautivos. Boletín Técnico de la Fundación Vida Silvestre Argentina, n. 55, p. 39-50, 2001.

Vicente Neto, J. Caracterização físico-química, colesterol e ácidos graxos da carne de jacarédo-pantanal (Caiman yacare Daudin, 1802) oriundo de zoocriadouro e habitat natural. 2005, 122p.Dissertação (Mestrado em Ciência dos Alimentos) Universidade Federal de Lavras - Lavras - MG. 
Vienet, V. Nutritional disorders in the green iguana (Iguana iguana). Point Veterinaire, v. 31, n. 205, p. 125-133, 2000.

Yang, Z.; Whyte, A. \& Attygalle. Reptilian chemistry: characterization of a family of dianeackerone-related steroidal esters from a crocodile secretion. Proc Natl Acad Sci, n. 96, p. 12251-12256, 1999.
Recebido em julho 15, 2014

Aceito em Setembro 3, 2014

License information: This is an open-access article distributed under the terms of the Creative Commons Attribution License, which permits unrestricted use, distribution, and reproduction in any medium, provided the original work is properly cited. 